This is a post-peer-review, pre-copyedit version of an article published in Clinical Drug Investigation. The final authenticated version is available online at:

https://doi.org/10.1007/s40261-020-00991-7 


\title{
Economic Impact of Schizophrenia from hospital and social security system perspective in Italy
}

\author{
Mennini Francesco Saverio ${ }^{1,2^{*}}$, Marcellusi Andrea ${ }^{\mathbf{1 , 2 *}}$, Gazzillo Simone ${ }^{1}$, Nardone Claudia ${ }^{1}$, \\ Sciattella Paolo ${ }^{1}$, Migliorini Raffaele ${ }^{3}$, Trabucco Aurilio Marco ${ }^{4}$, Amore Mario ${ }^{5}$, Brugnoli Roberto ${ }^{6}$
}

1. Economic Evaluation and HTA (EEHTA), CEIS, Facoltà di Economia, Università di Roma "Tor Vergata", Italia.

2. Department of Accounting Finance and Informatics, Kingston University, London, UK.

3. Ufficio di Coordinamento Medico Legale, Istituto Nazionale Previdenza Sociale (INPS), Roma, Italia

4. Dipartimento di Medicina e Scienze della Salute, Università degli Studi del Molise

5. Università di Genova

6. Università degli Studi di ROMA "La Sapienza"

Corresponding author: Dr Andrea Marcellusi

Institute: CEIS-Economic Evaluation and HTA (EEHTA) - Faculty of Economics

University: University of Rome "Tor Vergata", Rome, Italy.

Address: Via Columbia 2

Postal code: 00133 Rome - Italy

E-mail: andrea.marcellusi@uniroma2.it

Running header:

Economic burden of Schizophrenia in Italy. 


\section{Abstract}

\section{Background and Objective}

Schizophrenia is one of the mental disorders with the highest economic and social costs, with an important burden on patients, caregivers and society.

The objective of this study is to estimate the direct and social security costs of schizophrenia in Italy. As far as direct costs are concerned, those related to hospitalizations and pharmaceutical expenditure have been analysed, while, disability benefits (DB) and incapacity pensions (IP) have been considered for the social security costs.

\section{Methods}

In order to provide an economic burden of schizophrenia using the RWD (Real World Data) method, we have analyzed the main regional and national databases related to hospitalizations and pharmaceuticals.

Hospitalizations have been analyzed considering the Hospital Information System, which collects all the information regarding hospital discharges from all public and private hospitals (psychiatric wards or residential facilities have not been considered). Hospitalizations with a discharge date between 2009 and 2016, with a primary or secondary diagnosis of schizophrenia (ICD9CM 295.xx) were selected. Hospital costs have been estimated considering the national tariffs associated with each selected hospitalization.

In addition, using the same inclusion criteria, the average DBs (for workers with reduced working capacity) and IPs (for workers without working capacity) provided each year have been analyzed from the database of social security benefit applications.

The estimate of pharmaceutical expenditure has been prepared based on the OsMed 2018 Report (Italian Medicines Agency, latest issue $18^{\text {th }}$ July 2019).

A one-way deterministic sensitivity analysis was conducted to examine the robustness of the results.

\section{Results}

In Italy, from 2009 to 2016, schizophrenia had an important economic impact from a social perspective. On average, 13,800 patients were hospitalized, with an average of 2.98 hospitalizations per patient. From the National Health Service (NHS) perspective and with specific reference to hospitalizations, the annual economic burden was $€ 101.4$ million, with an average cost per patient of $€ 7,338$.

On the other hand, pharmaceutical expenditure amounts to over $€ 147$ million each year. Residential, semi-residential and specialist facilities amount to about $€ 1$ billion. 
Again, schizophrenia led to about 15,000 recipients of social security benefits (DB and IP) yearly from 2009 to 2015, with an average annual expenditure of $€ 160.1$ million (average cost per patient $=€ 10,675)$.

\section{Conclusions}

Our study estimates an economic burden of schizophrenia of $€ 1,250$ million per year of direct costs, of which $20 \%$ is related to hospitalizations and pharmaceutical expenditure. With regard to social security benefits, an average annual expenditure of $€ 160.1$ million was calculated (average cost per patient $=€ 10,675)$.

\section{Key Points}

Economic burden of Schizophrenia in Italy.

Schizophrenia had an important economic impact from a social perspective.

The trend over the years is increasing for IPs, even though is decreasing for hospitalizations and DBs. 


\section{Introduction}

Schizophrenia is considered one of the most severe and debilitating mental disorders with high social and economic costs for patients, caregivers and society as a whole [1].

Epidemiological studies report a uniform prevalence rate among the most developed countries $(0.3 \%-0.7 \%)[2,3]$. The mortality rate is more than double [4] compared to that of the general population, mainly due to suicides and cardiovascular diseases, with a higher risk of (psychiatric and non-psychiatric) comorbidity [5].

The treatment and care of patients diagnosed with schizophrenia cover between $1.5 \%$ and $3 \%$ of total national healthcare expenditure in more developed countries [4, 6], and 22\% [7] of the costs associated with mental disorders.

In Europe the economic impact of psychotic disorders in 2010 amounts to $€ 93.9$ billion, of which $69 \%$ is due to indirect costs only [1]. In fact, it is estimated that the unemployment rate of patients with schizophrenia is more than double compared to that of the general population [8,9], and $51 \%$ of them receive an incapacity pension in Italy [8]. Consequently, indirect costs are fundamental to estimate the overall impact of schizophrenia, which is a chronic and early disease, in most cases arising during adolescence [10]. In addition, it is essential to allocate economic resources efficiently in the therapeutic area. Therefore, the administration of highly effective drugs and the continuity of treatment are also important.

It has been demonstrated, in fact, that non-adherence to pharmacological treatments is related to the onset of psychotic symptoms. This could lead to readmission to psychiatric wards or residential facilities and, consequently, higher costs for the National Health Service (NHS) [7].

For these reasons, non-adherence to treatment is the most common cause of re-hospitalization (about $40 \%$ of new hospital admissions) and relapses, often characterized by more serious episodes [7, 11, $12]$.

The objective of this study was to measure the economic impact of schizophrenia in Italy by estimating the direct and social security costs of treatment, care and management of diagnosed patients. The estimate of the annual economic burden could be considered as an insight to improve the efficacy and effectiveness of patient's care, helping the decision maker to better allocate the available resources. 


\section{Data and methods}

\subsection{Estimate of direct costs}

As far as the direct costs of schizophrenia are concerned, those related to drugs and hospitalizations have been considered.

The analysis of hospital care for the treatment of schizophrenia was conducted using the data from the Hospital Discharge forms (HDF) available for the period 2008-2016, containing information related to all ordinary and day-hospital admissions nationally.

In particular, the hospital activity per single year was described by selecting, for the study period, all subjects with at least one hospital admission with a schizophrenic psychosis related diagnosis (diagnosis ICD 9 CM code: 295.xx) as main or secondary diagnosis. Specifically, ICD code 9 CM 295 includes simple schizophrenia (295.0), disorganized schizophrenia (295.1), catatonic schizophrenia (295.2), paranoid schizophrenia (295.3), acute schizophrenic episode (295.4), latent schizophrenia (295.5), redisual schizophrenia (295.6), schizoaffective schizophrenia (295.7), other specified types of schizophrenia (295.8) and unspecified schizophrenia (295.9).

The theoretical value of hospitalizations was estimated on the assumption that each admission is remunerated according to the national tariffs (Ministerial Decrees of $12^{\text {th }}$ September 2006 and $18^{\text {th }}$ October 2012 [13-14]). The DRG (diagnosis-related group) system aggregates all activities, including surgeries, drugs administered, materials and personnel spent for each diagnosis and assigns the reimbursement rate. This value corresponds to the total amount of all operations performed, which must be reimbursed to the hospital.

Under the DRG-based reimbursement system, each hospitalized patient is assigned to a group of homogeneous diagnostic cases. Therefore, patients with the same DRG values are assigned the same reimbursement expenses.

In the schizophrenic Psychosis, the DRG associated with almost all detected admissions was the medical DRG 430 "Psychosis", which covers $88.6 \%$ of admissions.

As far as the pharmaceutical expenditure is concerned, antipsychotics (class N05A), whose amount is indicated in the OsMed 2018 Report (Italian Medicines Agency, latest issue $18^{\text {th }}$ July 2019)[15], have been taken into consideration. OsMed Reports by Italian Medicines Agency provide data of medicines consumption and expenditure in the general population in Italy. Antipsychotics are broken down into "Typical Antipsychotics" and "Atypical Antipsychotics and others". However, not all antipsychotics are used exclusively in patients suffering from schizophrenia. The percentages of drugs used for schizophrenia were identified thanks to expert opinion. In particular, $90 \%$ of typical 
antipsychotics and $50 \%$ of atypical antipsychotics and others are attributable to schizophrenia. A board of two experts psychiatrists with high experience has been built. The psychiatrists participated in two expert meeting boards and are co-authors of our study.

\subsection{Social security cost estimate}

To estimate the social security costs related to schizophrenia, the National Social Security Institute (INPS) database was used, containing the number of applications submitted each year, from 2006 to 2015, for each service and the related opinions (acceptance or rejection) expressed by medical managers, with an indication of prevailing and any secondary diagnosis, based on the International Classification of Diseases, ninth revision (ICD-9-CM).

The Medical Centres (MLC) of the National Social Security Institute carry out an overall assessment of the applicant's physical and mental health conditions and accept the application, providing the benefit based on the presence of one or more disabling diseases.

Law no. 222/84 provides for the requirements to obtain the benefits being analysed: the Disability Benefit (DB) and the Incapacity Pension (IP). In order to obtain these allowances, a disability of more than $67 \%$ is required to obtain the benefit, and $100 \%$ (absolute and permanent incapacity for work) for the pension, as well as five years of contribution and insurance, three of which in the five years preceding the date of submission of the application. Therefore, the allowances considered are economic benefits addressed, in case of an accident or illness, to all the working categories under the National Social Security Institute system.

Similarly to the hospitalisation costs, the diagnosis code ICD-9-CM 295.xx was used to select successful applications for the two social security benefits for workers with a primary or secondary diagnosis of schizophrenic psychosis.

Starting from the successful applications, the recipients of the diseases in question were first estimated, i.e. the number of DBs and IPs actually paid by the National Social Security Institute each year, and finally the costs [17-18].

\subsection{Sensitivity Analysis}


One-way deterministic sensitivity analysis (DSA) was performed to evaluate the impact of input parameters on the results. Such analysis consists of changing one input parameter at a time, according to the minimum and maximum values found in the literature or assumed by the authors. In this specific case, the minimum and maximum values were defined assuming $\pm 10 \%$ variability for each parameter. In particular, we observed the variations of total annual expenditure by changing the following parameters:

- Hospitalization mean annual costs;

- DBs mean annual costs;

- IPs mean annual costs;

- Percentages of typical and atypical antipsychotics used for schizophrenia obtained by expert opinion. 


\section{Results}

\subsection{Direct costs}

\subsubsection{Pharmaceutical expense}

The results obtained will be shown separately with regard to the NHS and the social security system.

In the 2018 OsMed report on the use of drugs in Italy, the total annual expenditure for antipsychotics in 2018 was $€ 275.9$ million (Table 1), of which $91.6 \%$ is attributable to the sub-group Atypical antipsychotics and others (€ 252,7 million).

Table 1. Pharmaceutical expenditure for antipsychotics. Italy 2018

\begin{tabular}{|c|c|c|c|c|c|c|}
\hline $\begin{array}{c}\text { Group } \\
\text { Sub-group }\end{array}$ & $\begin{array}{c}\text { Total } \\
\text { Expenditure } \\
\text { (million } € \text { ) }\end{array}$ & $\begin{array}{c}\text { Expenditure } \\
\text { NHS (\%) }\end{array}$ & $\begin{array}{c}\text { Per Capita } \\
\text { Expenditure }\end{array}$ & $\Delta \% 18-17 *$ & $\begin{array}{c}\text { DDD/1000 } \\
\text { ab die** }\end{array}$ & $\begin{array}{c}\Delta \% \\
18-17\end{array}$ \\
\hline Antipsychotics & 275.9 & 1.3 & 4.56 & 5.8 & 9.6 & 2.6 \\
\hline $\begin{array}{c}\text { Atypical } \\
\text { antipsychotics } \\
\text { and others }\end{array}$ & 252.7 & 1.1 & 4.18 & 6.4 & 7.0 & 3.8 \\
\hline $\begin{array}{c}\text { Typical } \\
\text { antipsychotics }\end{array}$ & 23.2 & 0.1 & 0.38 & 0.0 & 2.6 & -0.6 \\
\hline
\end{tabular}

Source: 2018 OsMed report, The use of drugs in Italy

*\% Change 2017-2018. ** defined daily dose weighted by the population (1,000 residents).

Abbreviations: NHS - National Health Service, DDD - defined daily dose.

Applying the percentages by expert opinion to the values identified in the OsMed report, the pharmaceutical expenditure for antipsychotics directly attributable to the treatment of schizophrenia is $€ 147.2$ million, of which 20.9 million for typical antipsychotics and $€ 126.3$ million for atypical ones. 


\subsubsection{Cost of hospitalizations}

Through the methodology previously indicated, over the period 2008-2016, an average of 13,820 subjects annually who experienced at least one hospital admission, together with a primary or secondary diagnosis of schizophrenic psychosis were identified from the flow of Hospital Discharge Forms. The types of schizophrenia with the highest number of subjects were paranoid schizophrenia (about $40 \%$ of patients), schizoaffective schizophrenia (about 32\%), unspecified schizophrenia (about $17 \%$ ) and residual schizophrenia (14\%). With reference to the type of activity, acute subjects represent almost $95 \%$ of total subjects.

On the other hand, as far as direct costs incurred by the NHS for hospitalizations (Table 2) are concerned, with regard to the subjects identified, the average annual expenditure is over $€ 101$ million. In terms of costs, hospital admissions in the acute stage of the disease led to an average annual expenditure of $€ 76.7$ million, corresponding to $75.6 \%$ of the total annual cost. Rehabilitation and long-term care treatments are associated with a cost of $€ 9.8$ million (9.7\%) and $€ 14.9$ million $(14.6 \%)$ respectively.

Table 2- Cost of admissions with primary or secondary diagnosis of schizophrenia. Annual average values (2008-2016)

\begin{tabular}{|c|c|c|c|c|c|}
\hline Code & Diagnosis & $\begin{array}{c}\text { Acute } \\
\text { patients }(€)\end{array}$ & $\begin{array}{c}\text { Re-habiliation } \\
(€)\end{array}$ & $\begin{array}{c}\text { Long-term } \\
\text { hospitalization } \\
(€)\end{array}$ & Total $(€)$ \\
\hline 295.0 & Simple type & 4.448 .090 & 507.134 & 1.576 .912 & 6.532 .136 \\
\hline 295.1 & Disorganized type & 4.359 .317 & 441.374 & 1.117 .130 & 5.917 .821 \\
\hline 295.2 & Catatonic type & 739.407 & 46.495 & 54.537 & 840.438 \\
\hline 295.3 & Paranoid type & 25.249 .543 & 3.075 .368 & 5.314 .064 & 33.638 .975 \\
\hline 295.4 & Acute schizophrenic episode & 2.580 .531 & 99.336 & 87.691 & 2.767 .558 \\
\hline 295.5 & Latent schizophrenia & 1.611 .305 & 227.832 & 72.955 & 1.912 .092 \\
\hline 295.6 & Residual schizophrenia & 6.863 .935 & 946.244 & 2.823 .840 & 10.634 .018 \\
\hline 295.7 & Schizoaffective type & 19.773.731 & 3.160 .211 & 2.348 .199 & 25.282 .141 \\
\hline 295.8 & $\begin{array}{l}\text { Other specified types of } \\
\text { schizophrenia }\end{array}$ & 2.398 .530 & 243.673 & 89.347 & 2.731 .550 \\
\hline 295.9 & Unspecified schizophrenia & 8.665 .527 & 1.103 .567 & 1.382 .027 & 11.151 .121 \\
\hline Total & Schizophrenic psychosis & 76.689 .915 & 9.851 .232 & 14.866.701 & 101.407 .848 \\
\hline
\end{tabular}

Source: Hospital discharge forms data processing

However, observing the trends over the period considered, a decrease in the annual number of patients can be noticed, which in turn leads to a decrease in the number of hospital admissions and therefore in the amount of direct costs related to hospitalizations. In particular, there was a $20 \%$ 
decrease in patients, from 2008 to 2016, and a 24\% reduction in admissions. The trends are reported in Figure 1.

As regards the trend in costs over time (Figure 2), there was a 17\% drop (from over $€ 111$ million spent in 2008 to around $€ 92$ million spent in 2016).

Figure 1. Trend of admissions and patients with primary or secondary diagnosis of schizophrenia (2008-2016)

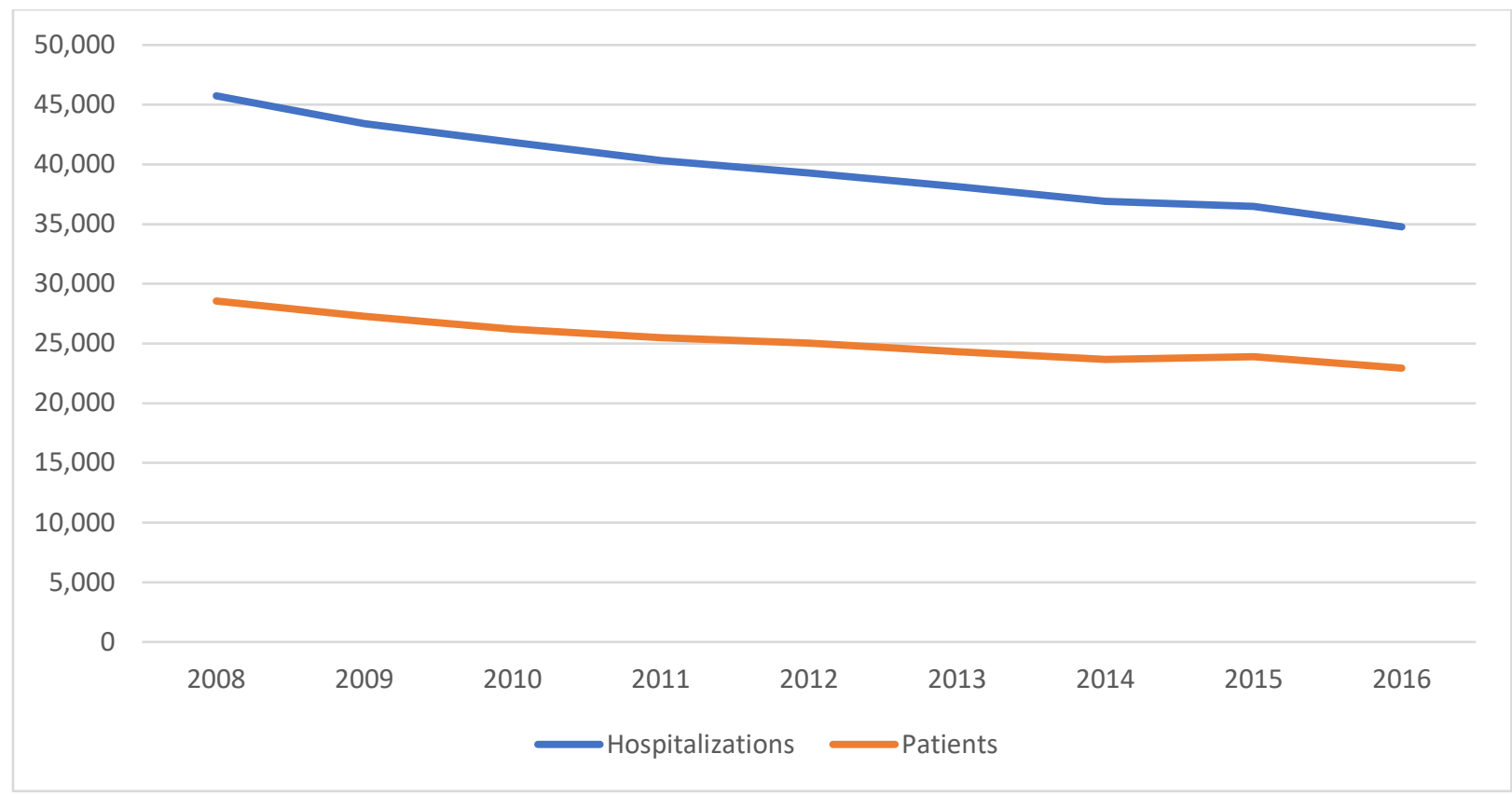

Soucre: Hospital discharge forms data processing 
Figure 2. Trend of costs due to hospitalizations for patients with primary or secondary diagnosis of schizophrenia (20082016)

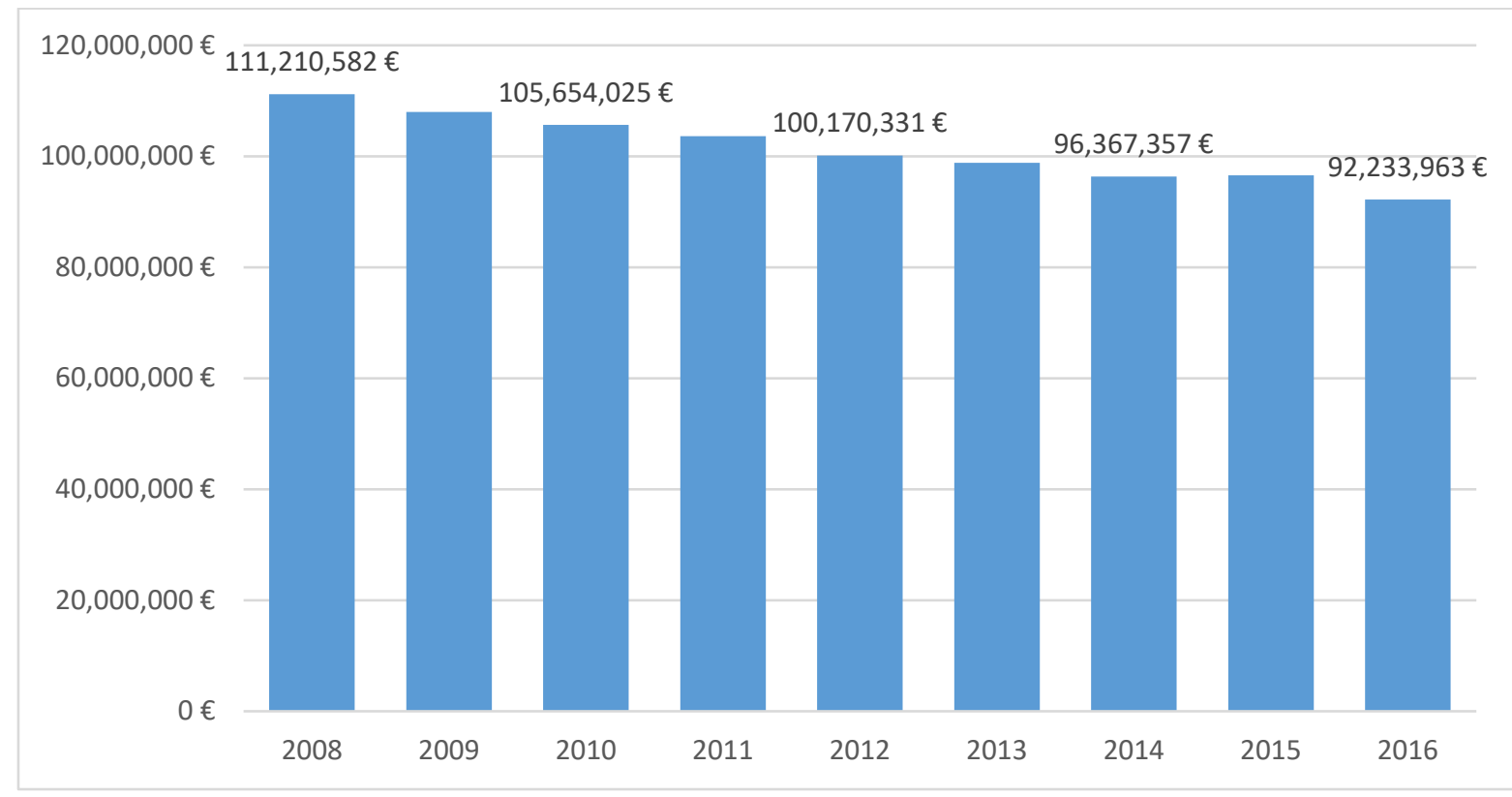

Source: Hospital discharge forms data processing

\subsection{Recipients and social security costs}

Recipients and related social security costs have been estimated taking into account, similarly to direct costs, the subjects with a primary or secondary diagnosis of schizophrenia. During the observed period, from 2009 to 2015, on average about 15,000 recipients are estimated annually. Of these, $48 \%$ receive a disability benefit, while the remaining 52\% receive an Incapacity Pension. Schizophrenia is also characterised by constant trend in IP recipients $(+5 \% 2015$ vs 2009 and $-3 \%$ 2015 vs 2010)and a decrease in DBs (-19\%).

In terms of expenditure, the total costs of social security benefits amounted to $€ 1.1$ billion over the 7 years observed, i.e. approximately $€ 160$ million spent each year. Most costs are due to IPs, about $62 \%$, for which $€ 100$ million are spent each year.

On the other hand, an average of $€ 60$ million was spent each year on DBs which account for about $38 \%$ of social security expenditure related to schizophrenia. In addition, as regards the spending trend of the two benefits, there was a 15\% increase for pensions, from 2009 to 2015 ( $+6 \% 2015$ vs 2010), and a $6 \%$ decrease for the disability benefit. Figure 3 shows the trends for recipients and costs.

From the perspective of the social security system, the types of schizophrenia weighing most in terms of number of recipients, and consequently in the amount of costs, are the paranoid type (about 
$31 \%$ of recipients of all types of schizophrenia), the schizoaffective type (about $22 \%$ of recipients), the other specified types of schizophrenia (15.5\%) and the residual schizophrenia (about 10\%).

Figure 3. Recipients and estimated costs for Disability benefits and Incapacity Pensions for Schizophrenia as primary or secondary diagnosis.

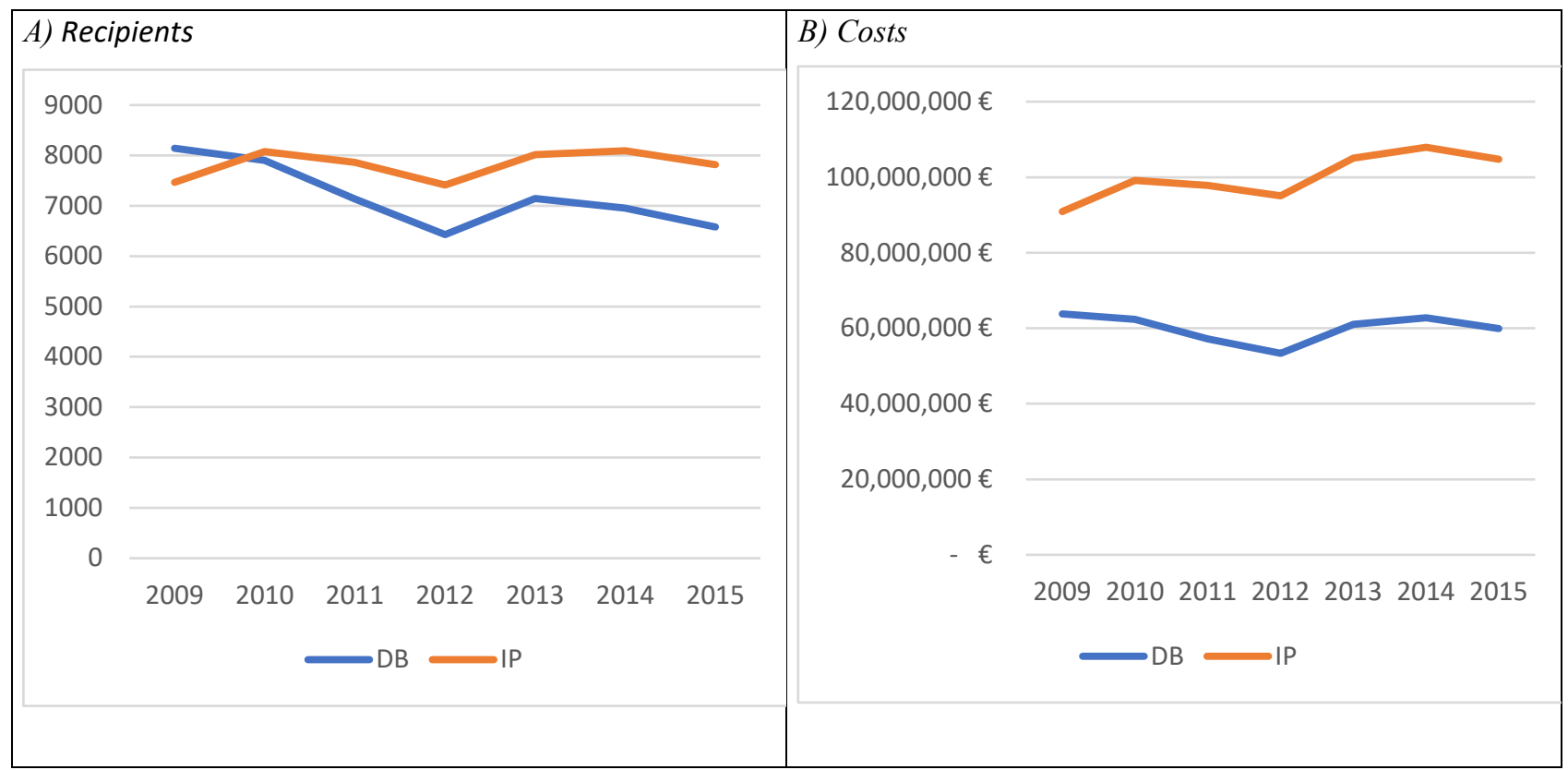

Source: INPS data processing.

Abbreviations: DB - Disability benefits, IP - Incapacity pensions.

Overall, the various cost categories analyzed during the study cause an annual expenditure related to schizophrenia of almost $€ 409$ million.

In particular, the average annual cost for schizophrenia is attributable for $61 \%$ to direct expenditure borne by the NHS (25\% hospitalizations and 36\% drugs), and for 39\% to social security expenses borne by INPS (15\% DB and 24\% PI). The overall results deriving from the analyses carried out are shown in Table 3 and Figure 4. 
Table 3. Estimate of total costs incurred each year for schizophrenia

\begin{tabular}{|c|c|c|l|}
\hline \multicolumn{2}{|c|}{ Cost category } & Average annual value & \multicolumn{1}{|c|}{ Source } \\
\hline \multirow{2}{*}{ Direct costs } & Hospitalizations & $€ 101,407,848$ & $\begin{array}{l}\text { Hospital discharge form flow + values } \\
\text { of national rates }\end{array}$ \\
\cline { 2 - 4 } & Drugs & $€ 147,230,000$ & 2018 OsMed report + expert opinion \\
\hline $\begin{array}{c}\text { Social } \\
\text { security } \\
\text { costs }\end{array}$ & DB & $€ 60,064,415$ & \\
\cline { 2 - 4 } & IP & $€ 100,092,417$ & INPS database \\
\hline \multicolumn{2}{|c|}{ Total } & $€ 408,794,680$ & \\
\hline
\end{tabular}

Source: Personal processing

Abbreviations: DB - Disability benefits, IP - Incapacity pensions, INPS - National Social Security Institute.

Figure 4. Distribution of the annual average cost of schizophrenia among the different cost categories analyzed

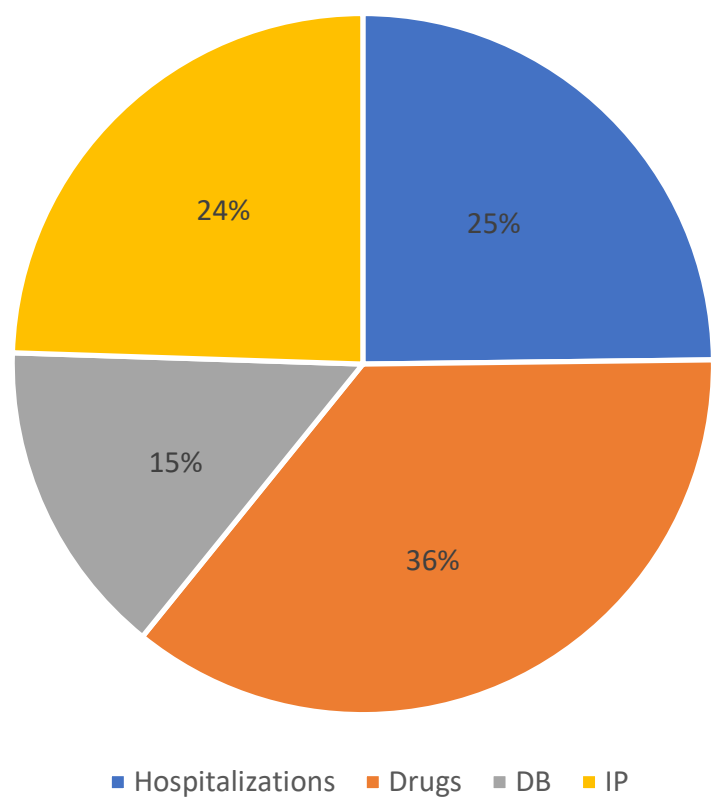

Source: Personal processing

Abbreviations: DB - Disability benefits, IP - Incapacity pensions. 


\subsection{Sensitivity Analysis}

Finally, Figure 5 shows the results of the deterministic sensitivity analyses. The variable that mainly afected the total annual expenditure was the percentage of Typical Antipsychotics used for schizophrenia. Changing this parameter assuming a variability of $\pm 10 \%$, we detected a variation in total annual expenditure (base case: $€ 408,8$ millions) to $€ 421,4$ millions and $€ 396,2$ millions respectively. The percentage of Atypical Antipsychotics used for schizophrenia was the parameter with the lowest influence on total annual expenditure. Assuming a growth and a reduction of this percentage by $10 \%$, the total annual cost would amout to $€ 406,7$ millions (Min) and $€ 410,9$ millions (Max). Changing the mean annual costs of Hospitalizations by $\pm 10 \%$, the total annual expenditure would be equal to $€ 398,6$ millions (Min) and $€ 418,9$ millions. Varying DBs and IPs by the same percentages assumed for other parameters, the overall annual cost would be equal to $€ 402,8$ millions (Min) - $€ 414,8$ millions (Max) and $€ 398,8$ millions (Min) - $€ 418,8$ millions (Max), respectively.

Figure 5. Results of the one-way deterministic sensitivity analyses (Tornado plot)

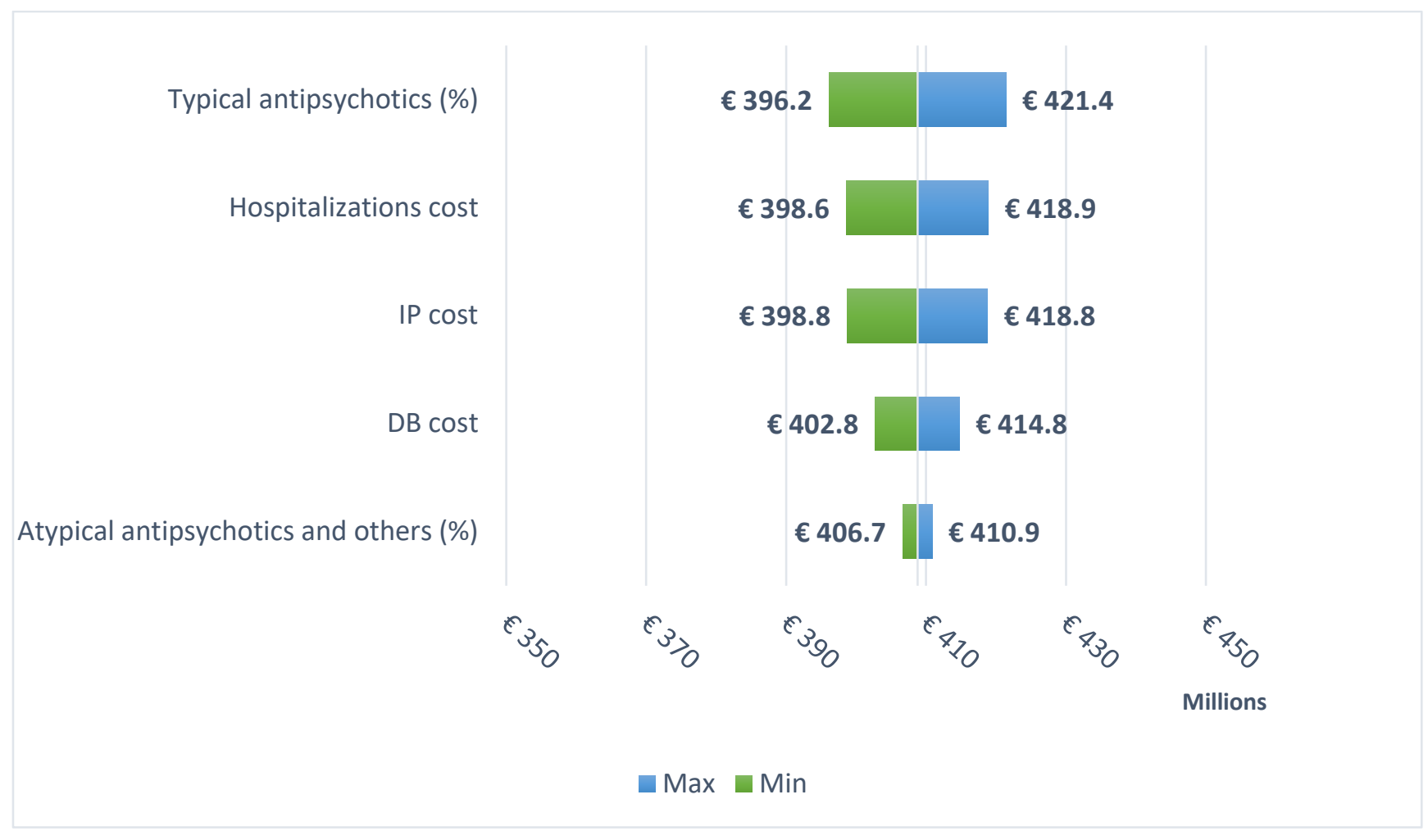

Source: Personal processing

Abbreviations: DB - Disability benefits, IP - Incapacity pensions. 


\section{Discussion}

The objective of the study was to estimate the direct costs of schizophrenia incurred by the NHS related to hospitalizations, and the cost of social security benefits such as DB and IP provided by the National Social Security Institute.

The main reason that led to the study was to provide an order of magnitude of a disease which is very disabling in terms of social security benefits, although characterized by a reduction in patients, hospitalizations and costs from the point of view of NHS. This is demonstrated by the high number of recognised IPs, and their increasing trend, compared to DBs.

In addition, a very significant annual economic impact can be observed. These cost items have been investigated as both direct costs and social security costs weigh on citizens. Specifically, the former are financed through general taxation, while the latter are financed through the contributions paid to the National Social Security Institute by working citizens.

With regard to the main results obtained, an average of 13,820 patients per year who received at least one admission, with a primary or secondary diagnosis of schizophrenia, was found in the reference period. Despite the increasing prevalence of schizophrenic patients $[2,3]$, there is a decreasing trend in hospitalized subjects $(-20 \%)$, number of admissions $(-24 \%)$ and related expenditure $(-17 \% \mathrm{~s})$. This is related to different factors: 1) preferences and financial constrain incentives to move patients management from inpatient to outpatient setting and 2) higher efficacy of the treatment for schizophrenia during the last decade that reduce the number of acute events.

On the other hand, the recipients of social security benefits $(15,000$ each year totally) decreased for DBs (-19\%) and remain constant for IPs (+5\% 2015 vs 2009 and -3\% 2015 vs 2010). Moreover, in line with the trend of benefits provided, the economic weight of IPs grew by $15 \%$, while that of DBs dropped by $6 \%$. In total, there is an average annual social security expenditure of over $€$ 160 million, of which about $62 \%$ is attributable to IPs. The total economic impact, considering all cost categories, is almost $€ 409$ million each year. Also in this case, additional analysis could investigate

The analysis shows some limitations. The study, in fact, refers to a limited period of time, both in the case of hospitalizations and services provided by the National Social Security Service. In addition, with regard to social security services, only the social security costs are taken into consideration, excluding those attributable to the social security services provided by INPS, which is instead more generally addressed to citizens (Civil Disability). The macrocategory of indirect costs should also include costs related to the loss of productivity of the patient, but also of the caregiver. Moreover, outpatient costs have not been considered. It is important to consider this cost item because increasingly cases (e.g. relapses) are managed at an outpatient level. This trend could partially explain 
the decrease in the number of hospital admissions and in the direct costs related to hospitalizations. Furthermore, different reference period for the analysis items (pharmaceutical expenditure, hospitalizations, social security costs) have been considered due to availability of data and material.

However, the study provides a picture, as well as an order of magnitude, of the burden of schizophrenia in Italy, taking into account two important perspectives, from which key features of the disease itself emerge. The study can also be considered innovative in terms of results achieved and data provided and it may represent a starting point for future developments that will broaden the perspectives of analysis and its time frame.

\section{Conclusions}

The study focused on direct costs of schizophrenia, linked to hospitalizations and drugs, and to the social security activity carried out by INPS through the provision of disability benefits and incapacity pensions. Among the main results obtained, it emerged that schizophrenia, in the perspective of the NHS, recorded a reduction in admissions and costs. On the other hand, pharmaceutical expenditure represents an important share among the cost items considered each year. With regard to social security costs, in line with the high disabling power of the disease treated, there was a reduction in the costs for DBs against an increase in the expenditure of IPs. 


\section{References}

[1] Gustavsson A, Svensson M, Jacobi F, et al. Cost of disorders of the brain in Europe 2010. Eur Neuropsychopharmacol 2011;21:718-79.

[2] Tansella M, De Girolamo G. The spread of mental disorders in the community. Rome:

Department of Medicine and Public Health, Psychiatric Section, University of Verona; National Project of Mental Health, Laboratory of Epidemiology, Health Institute, 2005.

[3] Saha S, Chant D, Welham J, et al. A systematic review of the prevalence of schizophrenia. PLoS Med 2005;2:e141.

[4] Altamura C, Galderisi P, Rocca A, et al. Schizophrenia today: epidemiology, diagnosis, course and models of care. Ital J Psychopathol 2014;20:223-43.

[5] Altamura AC, Serati M, Albano A, et al. An epidemiologic and clinical overview of medical and psychopathological comorbidities in major psychoses. Eur Arch Psychiatry Clin Neurosci 2011;261:489-508.

[6] Knapp M, Mangalore R, Simon J. The global costs of schizophrenia. Schizophr Bull 2004;30:279_ 93.

[7] Rocca P, Giugiaro M, Bogetto F. Compliance in the treatment of schizophrenia. Rivista di psichiatria 2006.

[8] Garattini L, Barbui C, Clemente R, et al. Direct costs of schizophrenia and related disorders in Italian community mental health services: a multicenter, prospective 1-year followup study. Schizophr Bull 2004;30:295-302.

[9] Garattini L, Rossi C, Tediosi F, et al. Direct costs of schizophrenia in Italian community psychiatric services. Pharmacoeconomics 2001;19:1217-25.

[10] Cortesi PA, Mencacci C, Luigi F, et al. Compliance, persistence, costs and quality of life in young patients treated with antipsychotic drugs: results from the COMETA study. BMC Psychiatry 2013;13:98.

[11] Niolu C, Barone Y, Bianciardi E, et al. Predictors of poor adherence to treatment in inpatients with bipolar and psychotic spectrum disorders. Riv Psichiatr 2015;50:285-94.

[12] Niolu C, Bianciardi E, Di Lorenzo G, et al. Enhancing adherence, subjective well-being and quality of life in patients with schizophrenia: which role for long-acting risperidone? Ther Adv Psychopharmacol 2015;5:278-88.

[13] Ministerial Decrees of $12^{\text {th }}$ September 2006. Reconnaissance and first update of the maximum tariffs for the remuneration of healthcare services 
[14] Ministerial Decrees of $18^{\text {th }}$ October 2012. Remuneration for acute hospital care, hospital rehabilitation and post-acute long-term care and specialist outpatient care

[15] OsMed 2018 Report - The use of drugs in Italy (AIFA, latetest issue 18/07/2019)

[16] INPS, Databases and financial statements - Statistics Observatories: https://www.inps.it/nuovoportaleinps/default.aspx?sPathID=\%3b0\%3b46437\%3b\&lastMenu=4643 7\&iMenu=12\&p4=2. Last access November 2020.

[17] Russo S., Mariani T.T., Migliorini R., Marcellusi A., Mennini FS., The economic burden of musculoskeletal disorders on the Italian social security pension system estimated by a Monte Carlo simulation. Reumatismo, 2015. 67(2): p. 45-56

[18] Marcellusi A., Rotundo M.A., Nardone C., et al. Osteoporosis: Economic Burden of Disease in Italy. Clinical Drug Investigation https://doi.org/10.1007/s40261-020-00904-8, 2020.

[19] Marcellusi A, Fabiano G, Viti R, et al. Economic burden of schizophrenia in Italy: a probabilistic cost of illness analysis. BMJ Open, February 2018

[20] National Institute of Statistics. Pensions and recipients. Year 2014. 2015. Last access November 2020. https://www.istat.it/it/archivio/175630

[21] Law 222/84, Legislative Decree 503/92.

https://www.gazzettaufficiale.it/eli/id/1984/06/16/084U0222/sg. Last access November 2020.

https://www.gazzettaufficiale.it/atto/serie_generale/caricaDettaglioAtto/originario?atto.dataPubblic $\underline{\text { azioneGazzetta=1992-12-30\&atto. codiceRedazionale=092G0550\&elenco30giorni=false. }}$.

Last access November 2020. 


\section{Declarations}

\section{Funding}

This paper was implemented by unconditional support of Angelini SpA.

\section{Conflicts of interest}

Mennini Francesco Saverio: no conflict of interest

Gazzillo Simone: no conflict of interest

Nardone Claudia: no conflict of interest

Sciattella Paolo: no conflict of interest

Marcellusi Andrea: no conflict of interest

Migliorini Raffaele: no conflict of interest

Trabucco Aurilio Marco: no conflict of interest

Amore Mario: no conflict of interest

Brugnoli Roberto: no conflict of interest

\section{Ethics Approval}

Not applicable

\section{Informed Consent}

Not applicable

\section{Consent for publication}

Not applicable

\section{Availability of data and material}

The data that support the findings of this study are available from the National Social Security Institute (INPS) but restrictions apply to the availability of these data, which were used under license for the current study, and so are not publicly available. Data are however available from the authors upon reasonable request and with permission of the National Social Security Institute (INPS). 